\title{
La Edad del Bronce en la Meseta, hoy
}

\author{
Catalina Galán Saulnier y Amparo Hernando Grande
}

\begin{abstract}
RESUMEN ABSTRACT

Actualmente son numerosos los Now adays there are large works of trabajos de investigación que tratan de sistematizar la Edad del Bronce en la Meseta, dando lugar a la identificación de diferentes facies $u$ «horizontes» que ponen de manifiesto la personalidid propia y el bagaje cultural desarrollado

por los habitantes de ese área geográfica. Pero este volumen de información, por otra parte, plantea problemas a la hora de analizar cual es realmente el estado de la investigación,

qué aspectos son los más/menos conocidos. Sintetizar esa información que existe hoy sobre el tema, por los motivos que exponemos no es tarea fácil, por ello aportamos una serie de consideraciones que a nuestro modo de ver deben ser tenidas en cuenta en el futuro de las investigaciones. investigation trying to systematize the Bronze Age in the Spanish Meseta giving place to the identification of different facies or "horizons» which show the own personality and cultural background developped by the inhabitans of that geographic area. But, on the other hand, this amount of information expounds problems when analyzing which is the real condition of the investigation, which aspects are the most/the less known. Summarize all the information existing about this subject these days is not a easy task. That is why we contribute with a series of considerations, that in our opinion, should be kept in mind in further investigations.
\end{abstract}

Hace alrededor de 20 años, cuando nos incorporamos al Proyecto de Investigación sobre la Edad del Bronce en La Meseta dirigido por el Prof. Nieto Gallo y Coordinado por el Prof. Sánchez Meseguer, el panorama con que nos encontramos resultaba bastante «deprimente», en tanto que todo parecía indicar que, frente al fuerte desarrollo cultural de que gozaron 
otras regiones peninsulares en esa época, la Meseta Central sin embargo había permanecido como un área cultural económica y socialmente atrasada casi aislada de los grandes Complejos Culturales que brillaron con luz propia a lo largo de los milenios III y II A.C., y en la que sólo un elemento el vaso campaniforme parecía «desentonar» por su espectacularidad entre un conjunto de restos arqueológicos aparentemente poco importantes y significativos.

No obstante, a medida que fuimos recopilando y ordenando la información, ese panorama fue convirtiéndose en verdaderamente atractivo, y poco a poco La Meseta se fue presentando ante nosotros más bien como «la gran desconocida», como un área de la que no sólo había más información de la que parecía sino también en la que, ya en aquel momento, se habían localizado yacimientos ciertamente interesantes y recuperado materiales de muy diversa índole y relevancia, todo lo cual ponía de manifiesto, en síntesis, dos realidades: que durante la Edad del Bronce «las cosas" habían sucedido en La Meseta de forma diferente a como se habían desarrollado en otras áreas y los acontecimientos habían cristalizado en un particular modo de desarrollo demográfico, económico, cultural y político, y por otro lado que, lejos de permanecer aislada de las áreas periféricas, La Meseta mantuvo unas relaciones con ellas de muy distinto carácter según los casos y momentos.

Pero hoy el panorama es sensiblemente diferente, y es que en estas últimas décadas no sólo se ha intensificado la investigación sino que, a nuestro modo de ver, también han cambiado sensiblemente sus planteamientos y modos de desarrollo.

De alguna manera, aunque con evidente retraso respecto a otros países, poco a poco se fueron dejando sentir entre los investigadores españoles las influencias de la "Nueva Arqueología", y uno de los primeros efectos de ello sobre la Prehistoria Meseteña se detecta en el hecho de que desde la década de los 70 empezaron a desarrollarse trabajos de investigación, que generalmente cristalizaron en Tesis Doctorales, que contemplaban no sólo el anáisis y estudio de lo ya conocido, sino también la búsqueda de nuevos datos que a priori ampliarían los conocimientos y rellenarían ciertas «lagunas de información existentes.

Así, de la mano de varios investigadores que dedicaron sus esfuerzos a la Submeseta Norte se identificaron poco a poco «horizontes" y facies culturales que empezaron a poner de manifiesto que esa amplia área geográfica no sólo no permaneció «en letargo" durante el Calcolítico y el Bronce Antiguo, puesto que sus habitantes desarrollaron su propia «personalidad cultural» plasmándola en lo que se vinieron a denominar «hori- 
zonte" Casaseca de las Chanas-Cazurra, facies Parpantique, etc., sino que incluso se incorporó al mundo de las poblaciones metalúrgicas bastante antes de lo que se había supuesto («horizonte» Las Pozas) y desde luego antes y al margen del «fenómeno» campaniforme.

Por otra parte, mientras en la Submeseta Norte la etapa correspondiente al Bronce Pleno seguía siendo una época bastante oscura de su Prehistoria reciente, el descubrimiento y la excavación de nuevos yacimientos empezaron a sacar a la luz los restos de los momentos más antiguos de lo que tradicionalmente se venía considerando como correspondiente al Bronce Final, es decir, del «horizonte» cultural denominado, según los casos, momentos y autores, Protocogotas I, Cogeces, Los Tolmos, etc.

Y mientras en la Submeseta Norte parecía que se iba despejando la incógnita de lo sucedido al comienzo y al final de la Edad del Bronce, en la Submeseta Sur sin embargo las excavaciones en las «motillas" de El Azuer y Los Palacios y las prospecciones llevadas a cabo en buena parte del territorio manchego, proporcionaron abundante información, luego recogida y elaborada también en algunas Tesis Doctorales, pero básicamente sobre el Bronce Pleno, período que se dio en caracterizar en La Mancha por una supuesta "Cultura de Las Motillas», así identificada no tanto por la representatividad de este tipo de yacimientos como porque durante cierto tiempo la de El Azuer fue el único suficientemente excavado.

Así, en los años 70 y 80 , varios investigadores ligados a la Universidad de Valladolid trabajaban en y para la Sumbeseta Norte, al tiempo que otros, esta vez ligados a las Universidades Autónoma y Complutense de Madrid, y luego a la de Granada, invertían sus esfuerzos en la zona Centro y en la Submeseta Sur, y a los resultados de esa lenta labor, que poco apoco fue cristalizando en nuevos trabajos de conjunto, en informes y memorias de las excavaciones realizadas en yacimientos ya conocidos y en otros de descubrimiento entonces reciente, e incluso en congresos regionales, locales, etc., empezaron a sumarse los que, consecuencia en buena parte de las nuevas políticas autonómicas, procedían no sólo de la labor desarrollada en el marco de distintos Proyectos de Investigación, sino también de la llevada a cabo en función de otros planteamientos muy diferentes al de la investigación sensu stricto, como los convenios con el INEM o las «excavaciones de urgencia».

Resultado de todo ello ha sido que en los últimos años han proliferado las publicaciones tanto de obras de conjunto que han pretendido sintetizar datos y opiniones e ir "ajustando" los nuevos descubrimientos al marco 
general más o menos comúnmente admitido, como de otras que, por el contrario, han planteado interpretaciones diferentes, pero al mismo tiempo han proliferado también las publicaciones monográficas - sobre yacimientos nuevos, materiales concretos o aspectos específicos-, de tal forma que el volumen de información actualmente disponible sobre la Edad del Bronce en La Meseta es no solamente elevado y diverso, sino también problemático a la hora de analizar cual es realmente ahora el estado de la investigación, qué aspectos son los más y mejor conocidos cuáles los más oscuros.

Más aún, si tratamos de no confundir «estado de la investigación» con "estado de la información", hoy por hoy bien podemos afirmar que mientras el de la segunda es mejor de lo que ha sido nunca, por su abundancia, aunque su calidad científica no sea siempre la deseable, sin embargo el panorama de la primera resulta bastante caótico en muchos aspectos y, aunque evidentemente cada zona y período ofrecen problemáticas específicas, no es menos cierto que se detectan una serie de "rasgos" bastante generales y entre los que debemos destacar, por ejemplo:

- Una ostensible falta de unidad de criterios en relación con la terminología utilizada para denominar las distintas fases de la Edad del Bronce Meseteña - aunque, dicho sea de paso, esto es algo extensible a toda la Prehistoria Peninsular-, falta de unidad que se refleja en la confusa identificación de los elementos definidores del calcolítico, si realmente existen, o en la utilización de términos referidos a materiales arqueológicos para indicar de alguna forma su correspondencia a diferentes épocas, tal y como se hace cuando se utilizan expresiones como épocas «precampaniforme», "campaniforme», "cogotiana», etc..

- Un arriesgado uso de los términos «horizonte cultural», "cultura» y «civilización», sin aclarar suficientemente en la mayoría de los casos el sentido y significado de cada uno de ellos y aplicándolos, tanto al hablar de fenómenos complejos, como el megalítico, como en relación simplemente con materiales arqueológicos tales como la cerámica campaniforme u otras decoradas, o también referidos a manifestaciones muy concretas que en ocasiones se han detectado en un solo yacimiento.

- Una falta de respeto por parte de ciertos investigadores hacia las opiniones de otros, pues no podemos considerar discrepancia científica, sino falta de respeto, cuando deliberadamente se ignoran argumentos e interpretaciones publicados, no rebatiéndolos con otros que tal vez aportasen la luz necesaria aún para determinados problemas, o cuando incluso se utilizan ideas publicadas por otros colegas como propias y sin mencionar su origen. 
- Un excesivo afán en muchos casos por hacer extensivo lo observado en un yacimiento o en unos pocos, a todo un territorio e incluso a toda una época, lo que, en definitiva, ha llevado con frecuencia a generalizar demasiado la presencia de ciertos elementos, rasgos, materiales, fechas, etc.

- Una tendencia bastante apreciable entre ciertos investigadores a considerar sus interpretaciones y planteamientos como «la última palabra al respecto", lo que conlleva un cierto convencimiento de estar en posesión de la verdad, suceda lo que suceda en y con investigaciones futuras.

Pensamos que lo expuesto hasta aquí habrá explicado, al menos en parte, el hecho de que el estado actual de la investigación sobre la Edad del Bronce en La Meseta, lejos de facilitar su identificación, comprensión, periodización, etc., hace sin embargo que su estudio resulte ciertamente complejo, tanto para quienes desde hace años nos dedicamos a él como para quienes lo aborden ahora.

La Meseta Central de la Península Ibérica es un área geográfica extensa, con un paisaje variado, en morfología y en recursos explotables para las comunidades de la Edad del Bronce, en el que todo parece indicar que valles fluviales y sistemas montañosos más que barreras $u$ obstáculos han sido focos de atracción en diferentes momentos y por distintas causas. Pero es evidente que el modo de ocupación y explotación de este vasto territorio también fue diverso a lo largo del III y $\|$ milenios A.C., en función de una serie de factores que aún hoy resultan de difícil identificación.

En cualquier caso, hay varios "fenómenos" que ahora se detectan en La Meseta y que esperamos que en un futuro, deseemos que no muy lejano, se puedan identificar con mayor claridad y definir más concretamente, que afectan a prácticamente toda La Meseta, y que de una u otra forma ponen de manifiesto su importancia como un área cultural con un relevante desarrollo económico y político durante la Edad del Bronce, y entre los que cabe señalar los siguientes:

* La extensión del fenómeno megalítico por zonas en las que antes se desconocía su existencia (Soria, Ávila) y su «convivencia» con otras formas de enterramiento hoy más y mejor conocidas y en el pasado poco valoradas, como los denominados "túmulos colectivos no megalíticos".

* La relación cada vez más evidente del desarrollo de la Edad del Bronce con la explotación de los recursos metalíferos del interior peninsular y, por supuesto, de otros muchos recursos cuya demanda aumentó sin duda con el aumento de población. 
* El desarrollo de las técnicas de explotación agropecuaria que bien pudo ser el factor determinante de un fuerte aumento demográfico y de un progresivo grado de sedentarización definitiva de la población.

* La muy probable, por no decir segura, existencia de patrones de comportamiento semejantes a los que en otras áreas permiten identificar estadios culturales correspondientes al Bronce Antiguo primero y al Bronce Pleno después, que parecen haberse plasmado en:

- La existencia de algunos núcleos de población fortificados, quizá más frecuentes durante el Bronce Antiguo en el área occidental, tal vez debido a una mayor relación con los núcleos portugueses, y sin embargo más «típicos en la zona oriental, y más concretamente en la Submeseta Sur, durante el Bronce Pleno, tal vez como resultado de una relación, diferente, esta vez con el Sureste y el Bronce Valenciano.

- Distintos modos de ocupación territorial y jerarquización de los asentamientos, diversidad deducible por una parte del modo de ausencia/presencia de determinadas variables de carácter socioeconómico, evidentemente diferentes para el 111 y el II milenios, que pone de manifiesto la existencia de núcleos de distinto grado de desarrollo económico, y deducible también, por otra parte, de la discontinuidad entre el Bronce Antiguo y el Bronce Pleno que de detecta básicamente en el abandono de asentamientos de diversas características al final del primero y la fundación de otros, también de distintos tipos y categorías, al comienzo del segundo.

- Un cambio evidente en el mundo funerario en el paso del Bronce Antiguo al Bronce Pleno, que se plasmó en un uso del enterramiento individual no sólo más frecuente sino también con nuevas formas de sepulturas (fosas revestidas de lajas, de mampostería, pithoi), mucho más acusado en la Submeseta Sur, muy posiblemente debido a la pujanza del bronce de La Mancha, que en la Submeseta Norte, donde una población más conservadora mantuvo el uso de monumentos megalíticos y cuevas; cabe señalar también que el escaso número de enterramientos del Bronce Pleno conocidos en la Submeseta Norte es también, por ausencia señal evidente de un cambio respecto a la etapa anterior que en cierto modo culminó con los «ocasionales» y «poco ortodoxos» enterramientos asociados a las gentes de Cogotas I, ya de finales del II milenio A.C.

* Un especial y arraigado gusto por las cerámicas decoradas, especialmente las incisas e impresas, causa del gran «éxito» que tuvieron en La Meseta el vaso campaniforme y otras cerámicas decoradas, durante el Bronce Antiguo, y las cerámicas tipo Cogotas I durante el Bronce Pleno y Final, y causa posiblemente también de que incluso en la vajilla de un complejo cultural caracterizado por sus cerámicas predominantemente 
lisas, el bronce de La Mancha, aparezcan también algunas incisas y/o impresas; mención aparte merece, lógicamente, èl «fenómeno» de la cerámica tipo Dornajos, presente en algunos casos junto a la campaniforme durante el Bronce Antiguo y especialmente concentrada en el yacimiento epónimo pero en un momento correspondiente ya al Bronce Pleno o Medio.

* Por último, hemos de referirnos a un doble aspecto cuya investigación apenas se ha apuntado hasta el momento, como es la relación existente entre los asentamientos y/o los lugares de carácter funerario y, por una parte, los conjuntos con arte esquemático, y por otra los "depósitos de bronces", yacimientos en ambos casos que hubieron de tener una necesaria relación con aquellos en los que, de una u otra forma, se han conservado los restos de la vida de sus autores o incluso de ellos mismos.

Evidentemente la investigación de la Edad del Bronce meseteña tiene abiertos en estos momentos otros muchos caminos que responden a varios de los aspectos que siguen planteando problemas aún no resueltos, lo que, a nuestro modo de ver, sigue haciendo de esas época y área geográfica sumamente atractivas para quienes seguimos trabajando en su conocimiento.

Y para concluir, queremos señalar ahora que somos conscientes de que lo expuesto en estas breves páginas responde a una personal y particular visión del tema en conjunto, visión que deliberadamente no acompañamos ni de demasiados ejemplos concretos ni de una bibliografía que, de no ser exhaustiva, siempre sería subjetivamente seleccionada, y todo ello en el ánimo de que el lector vea en estas líneas más una reflexión que una especie de "crónica» del estado actual de la investigación sobre la Edad del Bronce en la Meseta, un período de nuestra Prehistoria cuya identificación, periodización y cronología se presentan como ciertamente controvertidas en algunas de las publicaciones más recientes. 